University of Nebraska - Lincoln

DigitalCommons@University of Nebraska - Lincoln

September 2002

\title{
Review of the Genus Palaeophileurus (Coleoptera: Scarabaeidae: Dynastinae: Phileurini) with Description of Two New Species from Peru
}

Brett C. Ratcliffe

University of Nebraska-Lincoln, bratcliffe1@unl.edu

Follow this and additional works at: https://digitalcommons.unl.edu/entomologypapers

Part of the Entomology Commons

Ratcliffe, Brett C., "Review of the Genus Palaeophileurus (Coleoptera: Scarabaeidae: Dynastinae: Phileurini) with Description of Two New Species from Peru" (2002). Papers in Entomology. 24. https://digitalcommons.unl.edu/entomologypapers/24

This Article is brought to you for free and open access by the Museum, University of Nebraska State at DigitalCommons@University of Nebraska - Lincoln. It has been accepted for inclusion in Papers in Entomology by an authorized administrator of DigitalCommons@University of Nebraska - Lincoln. 
Published in Annals of the Entomological Society of America 95: 335-339. Used by permission.

"This article is the copyright property of the Entomological Society of America and may not be used for any commercial or other private purpose without specific written permission of the Entomological Society of America."

http://www.entsoc.org/pubs/periodicals/ann/index.htm 


\title{
Review of the Genus Palaeophileurus (Coleoptera: Scarabaeidae: Dynastinae: Phileurini) with Description of Two New Species from Peru
}

\author{
BRETT C. RATCLIFFE ${ }^{1}$ \\ University of Nebraska, W436 Nebraska Hall, Lincoln, NE 68588-0514
}

Ann. Entomol. Soc. Am. 95(3): 335-339 (2002)

\begin{abstract}
The eight species in the genus Palaeophileurus are reviewed, including the description of two new species from Peru: P. carbo Ratcliffe and P. erebus Ratcliffe. The diagnostic male parameres for all species are illustrated, and a distribution map is provided.
\end{abstract}

RESUMEN Se revisan las ocho especies del género Palaeophileurus, y se incluye la descripción de dos nuevas especies de Perú: P. carbo Ratcliffe y P. erebus Ratcliffe. Se proveen ilustraciones diagnósticas de los parámeros de todas las especies, y una mapa de distribución.

THE GENus Palaeophileurus was erected by Kolbe (1910) for a single species, Phileurus sclateri Bates, 1887, from Guyana. The genus is characterized by the absence of any pronotal furrow, fovea, or tubercle; the apex of the metatibia with only a single apical spine; simple basal tarsomere on the metatarsus; and the conspicuous opaque, black coloration of the elytra.

Endrödi $(1977,1985)$, in his synopses on the Dynastinae, provided a key to all New World phileurine genera and expanded the distribution of $P$. sclateri from Guyana to also include French Guiana and Colombia. Ratcliffe (1988) described two new species: P. brasiliensis and P. marcusoni, both from the Amazonian Brazil.

Dechambre (1996) proposed three new species names: P. fallax from French Guiana, P. panamensis from Panama, and P. proximus from the Amazon region of Peru and Brazil. Dechambre provided only a picture of the male genitalia but did not include a description of the species. All of these names are nomina nuda because they were not accompanied by a description or diagnosis in words as required by Article 13a (i) of the International Code of Zoological Nomenclature that was in effect at that time or by the most recent code's Article 13.1.1 (International Trust for Zoological Nomenclature 1985, 1999). Dechambre (1997) corrected this oversight by proposing the names again accompanied by a brief description of each. The date for these three species, therefore, is 1997 and not 1996.

Specimens of Palaeophileurus are exceedingly rare, and probably no more than 40-50 specimens are known to exist in collections throughout the world. Their rarity may result from genuinely small and/or dispersed populations, improper methods for attract-

${ }^{1}$ E-mail: bratcliffel@unl.edu. ing or collecting them, and our ignorance of where to look for them. A few specimens have been attracted to lights, but, in my experience, phileurines are not as readily attracted to lights as are many other dynastines. This may be due to their life history of the adults that live in and on rotting tree trunks and stumps where they do not usually "see" the occasional light trap. Other Dynastinae are more active at night, either flying to food plants or seeking mates, and so are more readily attracted to lights. Each of the two new phileurine species described herein were hand-collected while they were walking on rotting logs, one at night and the other during the day. Aside from these data, we do not know anything about the life cycle, immature stages, ecology, or habits of any of these elusive scarabs.

I briefly review each of the species of Palaeophileurus below, and describe two new species from Peru. The external anatomy of all the species is strikingly similar, and identification of the males is enabled only by referring to the form of the parameres (e.g., Figs. 2-17). In my opinion, it is not possible to reliably identify any females that are not collected with associated males because of the lack of distinctive external or internal characters, the sympatric occurrence of species, and the real likelihood of additional undescribed and sympatric species being found. Dechambre (1996) found some differences in the female genital plates, and I have observed differences in the apex of the prosternal process in one species, but these characters are not known in all the species and/or different enough between all the species to be diagnostic.

\section{Palaeophileurus brasiliensis Ratcliffe}

(Figs. 2, 3, and 18)

Palaeophileurus brasiliensis Ratcliffe 1988: 50. 


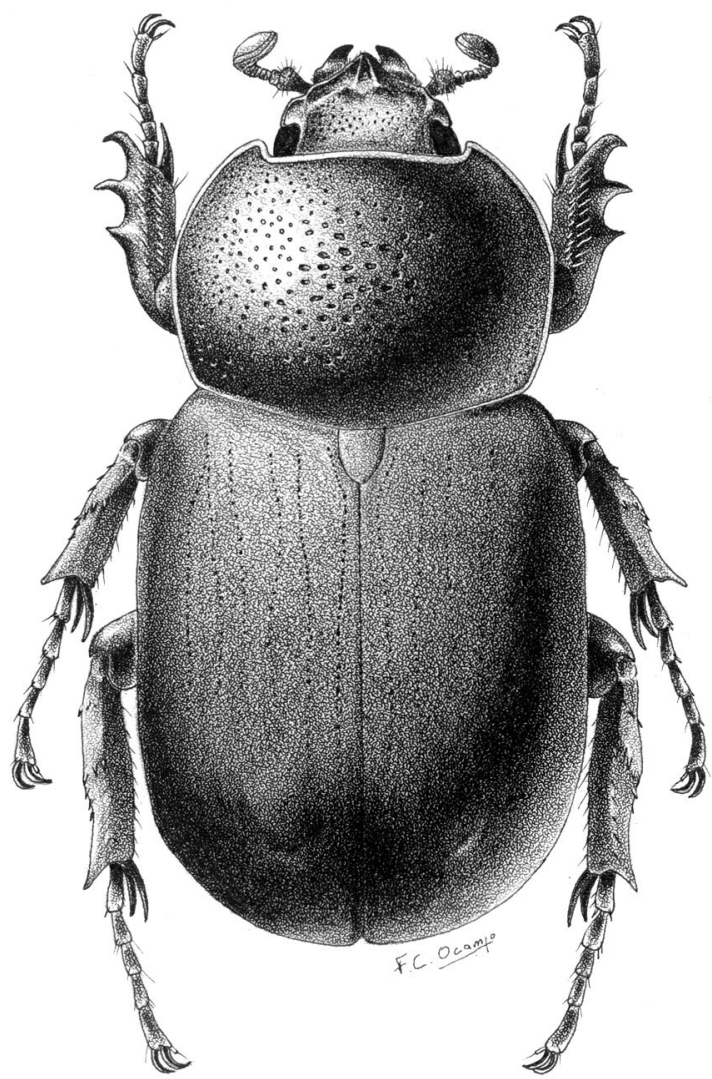

Fig. 1. Habitus of Palaeophileurus erebus Ratcliffe, new species, from Peru.

This species was described from three specimens taken at lights in the vicinity of Manaus, Amazonas, Brazil. This species has evidently not been collected since that time. It is separated from other species in the genus by the form of the parameres of the males or, if female, by association with the male. The male parameres are distinctive because of their relatively broad, lanceolate shape (Figs. 2-3).

\section{Palaeophileurus carbo Ratcliffe, new species} (Figs. 4, 5, and 18)

Type Material. Holotype labeled "PERU: Loreto Prov., $40 \mathrm{~km}$ NE Iquitos on Amazon R., Explorama Inn; 22-24-VIII-1992, Castner and Skelley, hand coll. at day." Holotype deposited at the University of $\mathrm{Ne}$ braska State Museum.

Description. Male. Length $22.9 \mathrm{~mm}$; width across humeri $12.1 \mathrm{~mm}$. Color black, pronotum slightly more shining than remainder of body. Head. Surface of frons between eyes weakly depressed, anterior rim of depression arcuate and feebly cariniform; surface of depression with transverse band of sparse, moderately large punctures. Frontoclypeal line with distinct, low tubercle either side of middle. Clypeus subtriangular, sides weakly bi-arcuate, surface nearly impunctate (with sparse, minute, shallow punctures); apex bluntly pointed, reflexed; weak carina extends from apex to base of each tubercle. Interocular width equals 4.1 transverse eye diameters. Mandibles with external edge arcuate. Antenna 10-segmented, club subequal in length to antennomeres 2-7. Pronotum. Surface punctate; minute punctures sparse, mixed with larger punctures; large punctures transversely oval, moderate in density in anterior and posterior angles and along lateral margin, punctures becoming large on disc and smaller and sparser anteromedially. Sides with marginal bead, base lacking bead. Anterior angles acute, posterior angles obtusely angulate. Elytra. Surface densely shagreened, with six rows of punctures between suture and humerus, rows not impressed, punctures small and shallow. Intervals with a few, sparse punctures. Side behind humerus with one short row of small punctures. Apical umbone prominent. Pygidium. Surface densely punctate; punctures moderately large, deep, nearly contiguous, setigerous; setae minute, tawny in color. In lateral view, surface evenly convex. Legs. Protibia tridentate, teeth evenly spaced. Metatibia with upper angle of apex produced as triangular spine, remainder of apex lacking teeth or spinules. Venter. Prosternal process long, apex bluntly trilobed, posterior lobe tuberculate, one-sixth size of each anterior lobe, below plane of anterior lobes. Last abdominal sternite densely rugopunctate. Parameres (Figs. 4-5): Symmetrical, elongate, each paramere with nearly bulbous apex, sides just before apex rounded (not angulate). In lateral view, apex broadly rounded to apical point.

Diagnosis. Dorsally, this species resembles all others in the genus. The prosternal process is different from that in P. sclateri, P. panamensis, $P$. erebus, $P$. brasiliensis, and P. marcusoni because the posterior lobe of the apex is very small $(\approx 1 / 6$ size $)$ compared with the two anterior lobes whereas in the other species it is about half the size of each anterior lobe.

The male parameres (Figs. 4 and 5) are distinctive and enable identification of this species. This is the only species of Palaeophileurus where the apices of the parameres are bulbously rounded; the apices of the parameres of $P$. erebus are expanded (but not bulbous), and they are also angulate on the lateral edges just before the apex. In addition, the parameres of $P$. erebus are asymmetrical whereas they are symmetrical in P. carbo.

The specimen was hand-collected by Paul Skelley during the day on the surface of a log.

Etymology. From the Latin carbo, meaning coal or charcoal; in reference to the dull black color of this species.

\section{Palaeophileurus erebus Ratcliffe, new species}

(Figs. 1, 6, 7, and 18)

Type Material. Holotype labeled "PERU: Loreto Pr.: nr. jet. Rio Maranon and Ucayali. $73.5^{\circ} \mathrm{W}, 4.8^{\prime} \mathrm{S}$, 6-20-VIII-1994, P. Skelley, at night." Holotype deposited at the University of Nebraska State Museum. 

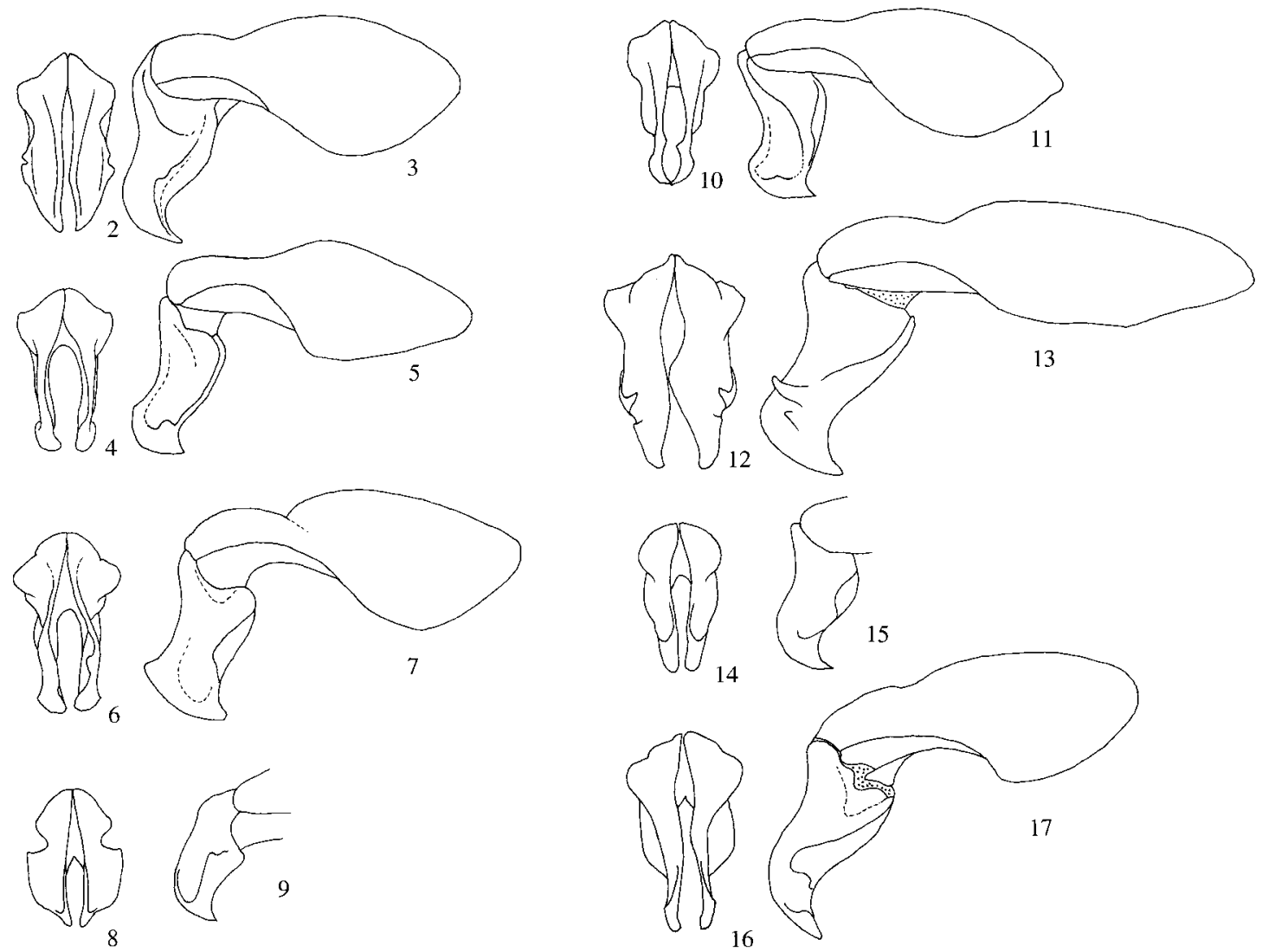

Fig. 2-17. Parameres of Palaeophileurus species: 2-3) P. brasiliensis Ratcliffe, 4-5) P. carbo Ratcliffe, new species, 6-7) P. erebus Ratcliffe, new species, 8-9) P. fallax Dechambre, 10-11) P. marcusoni Ratcliffe, 12-13) P. panamensis Dechambre, 14-15) P. proximus Dechambre, 16-17) P. sclateri (Bates).

Description. Male. Length $24.9 \mathrm{~mm}$; width across humeri $12.6 \mathrm{~mm}$. Color black, pronotum slightly more shining than remainder of body. Head. Surface of frons weakly depressed between eyes, anterior rim of depression arcuate and feebly cariniform, surface of depression irregularly punctate, punctures small and moderate mixed, small punctures moderate in density, moderate punctures sparse. Frontoclypeal line weakly tuberculate either side of middle. Clypeus subtriangular, sides strongly bi-arcuate, surface with small, sparse punctures; apex bluntly pointed, reflexed; weak carina extending from apex to base of each tubercle. Interocular width equals 3.6 transverse eye diameters. Mandibles with external edge arcuate. Antenna 10segmented, club subequal in length to antennomeres 2-7. Pronotum. Surface punctate; minute punctures sparse, mixed with larger punctures; large punctures moderate in density, becoming very large and distinctly transverse on disc and smaller and sparser anteromedially. Sides with marginal bead, base lacking bead. Anterior angles acute, posterior angles obtusely angulate. Elytra. Surface densely shagreened, with six weakly indicated rows of punctures between suture and humerus, rows not impressed, punctures small, shallow. Intervals appear impunctate. Side behind hu- merus with one short row of small punctures. Apical umbone prominent. Pygidium. Surface densely punctate; punctures moderately large, deep, nearly contiguous, setigerous; setae minute, tawny in color. In lateral view, surface evenly convex. Legs. Protibia tridentate, teeth evenly spaced. Metatibia with upper angle of apex produced into triangular spine, remainder of apex lacking teeth or spinules. Venter. Prosternal process long, apex bluntly trilobed, posterior lobe transverse, about half size of each anterior lobe, below plane of anterior lobes. Last abdominal sternite densely rugopunctate. Parameres (Figs. 6 and 7). Slightly asymmetrical, elongate, each paramere with weak angle on lateral edge just before apex, apex expanded. In lateral view, apex expanded, rounded.

Diagnosis. The male parameres (Figs. 6 and 7) are distinctive and serve to identify this species. The right (in caudal view) paramere of both P. erebus (Fig. 6) and P. marcusoni Ratcliffe (Fig. 10) has an angular tooth on the inside margin of the shaft, but the parameres are otherwise different. Palaeophileurus erebus has the upper edge of each paramere strongly carinate whereas P. marcusoni does not. Also, P. erebus 


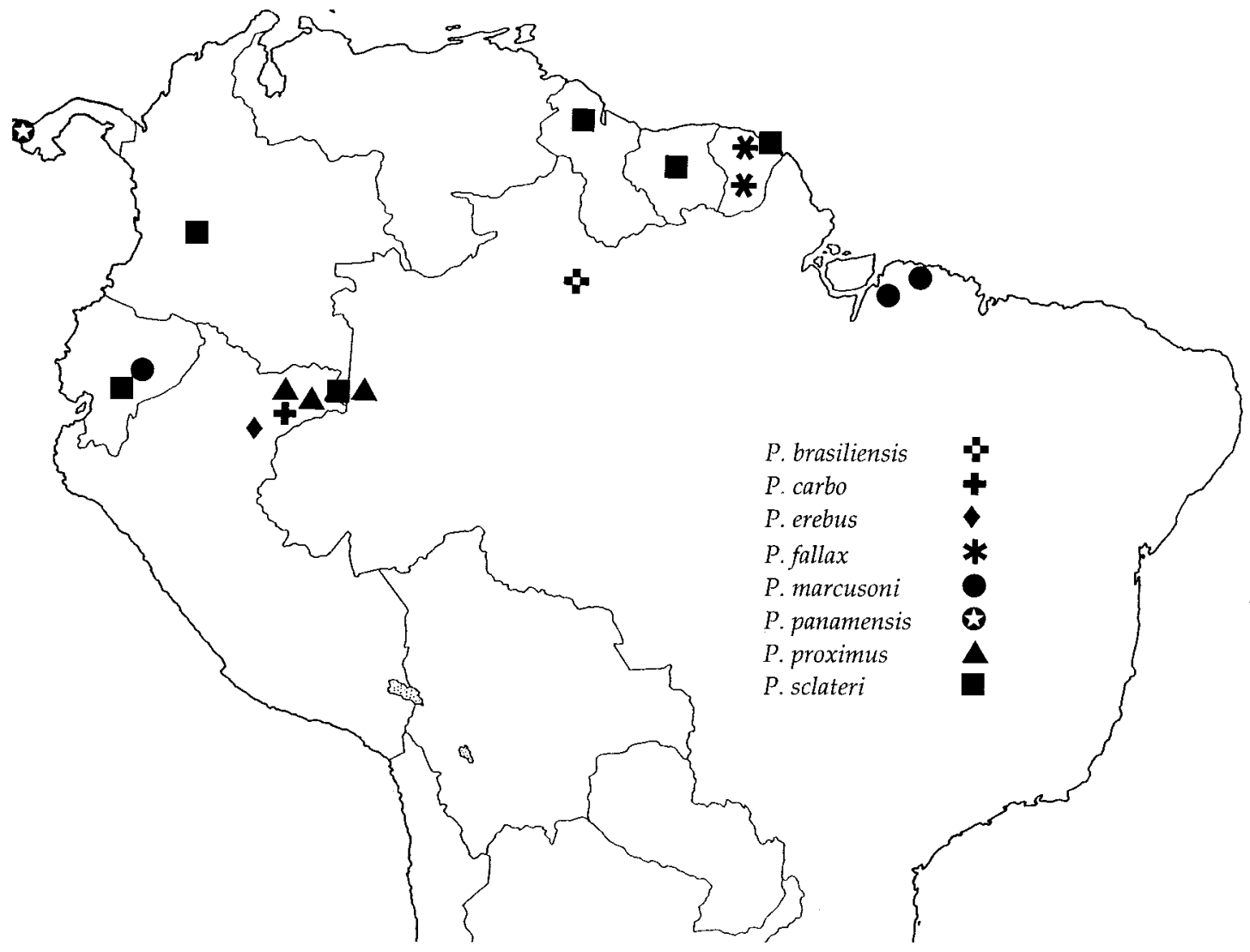

Fig. 18. Distribution of Palaeophileurus species.

lacks the distinctive, elongate "flange" present on the lateral edge of each paramere in P. marcusoni.

The specimen was hand-collected by Paul Skelley at night on the surface of a downed tree trunk.

Etymology. Named after Erebus, god of darkness, in reference to the black coloration of this beetle. Erebus also refers to the place of darkness in the netherworld, here used in loose reference to the dark habitat (log, humus, soil) where this species probably lives. In addition, we are IN Erebus vis-a-vis our knowledge about the biology and ecology of this species.

\section{Palaeophileurus fallax Dechambre}

(Figs. 8, 9, and 18)

Palaeophileurus fallax Dechambre 1996: 132. Nomen nudum.

Palaeophileurus fallax Dechambre 1997: 32.

This species was described from 15 specimens (males and females) from French Guiana where it seems to be widely distributed. The males are distinctive because of their very broad parameres (Figs. 8 and 9).

\section{Palaeophileurus marcusoni Ratcliffe}

(Figs. 10, 11, and 18)

Palaeophileurus marcusoni Ratcliffe 1988: 52.

This species was described from a single male specimen collected near Belém, Pará, Brazil. Six additional specimens were recorded since 1988 by Dechambre (1996): two specimens from Benevides and Bragança, both in Pará state, Brazil, and four specimens from Ecuador: road from Limón (Playa Gutierréz) to Méndez (Morona Santiago province), $\mathrm{km} 22.5$; the Loreto road and Misahuallí (both Napo province); and one specimen with no data.

This is one of only two species in the genus that has asymmetrical parameres (Figs. 10 and 11) (the other is P. erebus).

\section{Palaeophileurus panamensis Dechambre}

(Figs. 12, 13, and 18)

Palaeophileurus panamensis Dechambre 1996: 132. Nomen nudum.

Palaeophileurus panamensis Dechambre 1997: 32. 
Palaeophileurus panamensis is known only from "Chiriqui" in Panama, and the holotype is the only specimen known. The specimen was in the LeMolt collection at the Museum National d'Histoire Naturelle in Paris as early as 1908. It seems reasonable to assume, therefore, that the specimen may have been collected around the turn of the century. At that time, "Chiriqui" usually referred to the southern or eastern slopes of Volcan Barú (=Volcan Chiriqui).

No representatives of this species have been collected since that time in what is by now a fairly wellcollected area. Even allowing for the rarity of Palaeophileurus species, I wonder if this species is still extant in Panama. There is also the possibility that the specimen is mis-labeled.

The parameres of the male are unique in having a large, pointed, upwardly directed flange on each side (Figs. 12 and 13).

\section{Palaeophileurus proximus Dechambre}

(Figs. 14, 15, and 18)

Palaeophileurus proximus Dechambre 1996: 132. Nomen nudum.

Palaeophileurus proximus Dechambre 1997: 32.

Palaeophileurus proximus was described from a male (Rio Napo, Peru) and two females (Pebas, Amazonas, Peru, and São Paulo de Olivença, Amazonas, Brazil). Because the females were not collected with the male, I believe it is not possible to reliably assign to them the same name as the male holotype. At least four species are sympatric in this region: $P$. carbo, $P$. erebus, $P$. proximus, and $P$. sclateri. The two females may be considered conspecific with each other because the female genital plates are similar; the plates are different between some species (see illustration in Dechambre [1996]).

The parameres (Figs. 14 and 15) of the male are characterized by bluntly rounded apices and by the lateral margins elevated into a concave trough or "gutter."

\section{Palaeophileurus sclateri (Bates)}

(Figs 16-18)

Phileurus sclateri Bates 1887: 490.

Bates described this species based on a single male holotype from British Guiana (Guyana). Consequently, Dechambre's (1996) lectotype designation is invalid as is his designation of a "neallotype" for a specimen collected in 1920. The first known specimen of the opposite sex, while interesting, has no type standing whatsoever unless it is part of the original type series.

In caudal view, the parameres (Fig. 16) are vaguely similar to those of P. marcusoni (Fig. 10), but each paramere lacks the small tooth on its inner face that is present in P. marcusoni. In lateral view, the apex of the paramere is more elongate and tapering (Fig. 17) than in P. marcusoni, which is broad and blunt (Fig. 11).

Several specimens are known from French Guiana (Kourou), Guyana (no data), Colombia (Leticia, Villavicencio) (Endrödi 1977, 1985), and Dechambre (1996) recorded a male and female from Ecuador (Sucumbios and Cordillera de los Guacamayos). I have also examined a male from Ecuador (Rio Bobonaza).

\section{Acknowledgments}

I thank Paul Skelley (Florida State Collection of Arthropods) for providing the new species of Palaeophileurus and for graciously donating them to the University of Nebraska State Museum. Roger-Paul Dechambre (Museum National d'Histoire Naturelle, Paris) kindly loaned me his holotype of $P$. panamensis, and Vlada Maly (Prague, Czech Republic) loaned me a specimen of P. sclateri. I am very grateful to Federico Ocampo (University of Nebraska State Museum) for illustrating the habitus of P. erebus. Gail Littrell is thanked for the word processing. I acknowledge the generous assistance of Mary Liz Jameson, Andrew Smith, and Federico Ocampo (all University of Nebraska) for their critical review of the manuscript. This project was supported by an NSF/ PEET grant (DEB 712447) to B.C.R. and Mary Liz Jameson and an NSF/BS\&I grant (DEB 9200760) to B.C.R.

\section{References Cited}

Bates, H. W. 1887. Description of a new species, p. 490. In M. Jacoby (ed.), List of a small collection of Coleoptera obtained by Mr. W. L. Sclater in British Guiana. Proc. Zool. Soc. Lond. 3: 490-491.

Dechambre, R.-P. 1996. Le genre Palaeophileurus Kolbe, 1910 (Coleoptera, Dynastidae). Rev. Fr. Entomol. (N.S.) 18: $129-133$

Dechambre, R.-P. 1997. Compléments aux descriptions des espèces du genre Palaeophileurus Kolbe, 1910 (Coleoptera, Dynastidae). Rev. Fr. Entomol. (N.S.) 19: 32.

Endrödi, S. 1977. Monographie der Dynastinae. 8. Tribus: Phileurini, amerikanische Arten I. (Coleoptera). Folia Entomol. Hung. (N.S.) 30: 7-45.

Endrödi, S. 1985. The Dynastinae of the world. Dr. W. Junk, Dordrecht (46 plates).

International Trust for Zoological Nomenclature. 1985. International Code of Zoological Nomenclature, 3rd ed. International Trust for Zoological Nomenclature, London.

International Trust for Zoological Nomenclature. 1999. International Code of Zoological Nomenclature, 4th ed. International Trust for Zoological Nomenclature, London.

Kolbe, H. 1910. Ueber die Phileurinen Amerikas. Ann. Soc. Entomol. Belg. 54: 330-354.

Ratcliffe, B. C. 1988. New species and distributions of Neotropical Phileurini and a new phileurine from Burma (Coleoptera: Scarabaeidae: Dynastinae). Coleopt. Bull. 42: 43-55.

Received for publication 26 September 2001; accepted 4 January 2002. 